\title{
EDITORIAL
}

\section{Humans' Real Place on Earth}

$\mathrm{H}_{\text {ther }}^{\mathrm{u}}$ umans' most crucial place and activity on Planet Earth should, foremost and always, have due regard for their responsibility to and for The Biosphere. For not only is The Biosphere the sole habitat and, apart from energy from the Sun, life-support of all Humankind and Nature, but it is the only known source of life in the Universe - so that if there were no functioning Biosphere there would probably not for long be any persisting life of any kind anywhere. Yet there are serious students of the situation who believe that if humans go on breeding and behaving as profligately as they have been doing of late, not merely our current way of life but eventually all life on Earth would be endangered and could even cease to exist.

As there may well be no other source of life than Earth's fragile Biosphere, an ending of life on Earth could mean the entire extinction of life wherever it exists in the Universe. Accordingly there can surely be no greater responsibility for us all than doing whatever we can towards maintaining The Biosphere in a healthily functioning condition.

In our own many years of striving to warn humanity of the grave need for widespreed and often drastic action if an equable future for Earth and its surrounding Biosphere was to be reasonably assured (as recounted in our latest, penultimate Editorial, this present one being our positively last), it became increasingly and rather shockingly clear to us that very few, even of the intelligent and normally enlightened people the world over, see much beyond their immediate horizon environmentally, or have any real interests other than their own selfish concerns. The one ploy that tended to shake them was to ask what kind of a future they desired for their children and further descendents if any. Yet meanwhile the vast majority of as continue to be far too complacent in our pandominance.

Clearly the remedy for this tragic and even dangerous situation lies in pertinently informative education such as we have tried to instil through the journals we have founded and edited or at least encouraged, conferences we have planned, held, and edited the proceedings of, and other activities such as our around-theworld talks on the gravity of the situation as we saw it* - and still see it, hoping that our successor in the editorship of this Journal will continue to spread these beliefs and cognate imperatives.

Humankind being evidently the one species (among the millions of biota currently inhabiting Planet Earth) that has the intelligence to understand what it is doing in terms of its environmental future, and having fantastic providence-given resources for the doing, it behoves us to think and act primarily for The Biosphere's welfare, and henceforth be far more careful about everything we do that can affect our shared only habitat - which means practically everything, even if seemingly minor - for our own and Nature's future. We must not be dazzled by modern contraptions that may leave us thinking we can manufacture nourishing food or produce fresh water or living-space from nothing, but always practise due economy of these and other limited necessities of which there is currently often appalling wastage. So we must leave it to future generations to take the lead in showing and practising how these imperatives are to be achieved, being myself quite confident that, at least in the absence of any disastrous asteroidal or major meteoric impact or global calamity, they indeed can be achieved.

\section{NichOlas POLUNin Geneva, Switzerland 22 November 1995}

\begin{abstract}
,*Here we are reminded of the World Council For The Biosphere, which we conceived, established, and ran for the ten years of its active existence - until it became evident that more and more of the reasons for its establishment were being taken care of by ad hoc or other responsible bodies, leaving our World Council chiefly to look after Biosphere Day, Biosphere Clubs, and the search for funds especially for helpfully valuable allied Prizes. These last are our remaining ambition to see established; they should be annual and ancillary to a first major Biosphere Prize, include a satellite one in each of the five leading fields of biospheric importance which should be of sufficient value to enable recipients of demonstrated prize-winning capacity and developmental ability to carry on their approved work. These fields are land, sea, fresh water, renewable resources, and air (including stratosphere and climate).

We also think of worthy bodies we have helped (or at least encouraged) to start and now continue allegiance with, such as the International Society of Naturalists, The Foundation for Environmental Awareness, The Vernadsky International Centre for Biosphere Studies, and the International Energy Foundation. Moreover there are our continuing books' series of Cambridge Studies in Environmental Policy and Environmental Challenges, as well as our sole editorship and responsibility for publishing the muchneeded World Who Is Who and Does What in Environment \& Conservation - in case anybody should think we will be forsaking the environmental/conservational movement after undertaking our positively last International Conference on Environmental Future already some years ago and now relinquishing the Editorship of Environmental Conservation (apart from joining its Board of Advisory Editors and retaining responsibility for its section of Book Reviews). At least (and at last!) these changes should give us time to think properly henceforth about what we aspire still to perpetrate, including the ongoing World Who Is Who and certain books that really seem to be needed.

Also needed we feel strongly is the development outlined in prospect in the terminal footnote (on page 194 of our latest issue) to our penultimate editorial, namely of a global network of independent environmental/conservational watch-dogs which our Biosphere Clubs surely could and therefore should be encouraged to become, guided as to policy by a resurrected World Council For The Biosphere and having sufficient local media-clout to get publicity for action when necessary.
\end{abstract}

